\title{
Application of Surgical Safety Checklist in Operating Theatre at Al-Kindy Teaching Hospital \\ ${ }^{1}$ Laith N. Hindosh. ${ }^{2}$ Zuhair B. Kamal. ${ }^{3}$ Raed E. Rezqallah,
}

\section{ABSTRACT}

Background: A core set of checks have been incorporated into World Health Organization (WHO) WHO surgical safety checklist. Lack of access to basic surgical care remains a major concern in low-income settings.

Objective: We use a WHO surgical safety checklist items to improve team communication and cooperation to help in reduction of morbidity and mortality of surgical procedures.

Methods: This is a prospective study involving 300 patients after applying the 19 items of the surgical safety checklist with different types of operations had been operated in the surgical theater at AlKindy Teaching Hospital during the period $1^{\text {st }}$ of September 2016 until $^{\text {st }}$ of March 2017. We follow up the patients until 30 days after surgical intervention.

Results: After applying the 19 items of surgical safety checklist, the risk of the surgical site infection, respiratory complications, retained gauze and risk of blood loss $[14 \%, 4.6 \%, 1.3 \%$, and $2 \%$ respectively] was comparable to the results of the World Health Organization. Using the pulse oximetry in $94 \%$ and site marked in $65.3 \%$. In $64.6 \%$ of patients received antibiotic prophylaxis in which just $4 \%$ developed surgical site infection [SSI], while in extended regime $36.67 \%$ there is $10 \%$ developed SSI. No mortality reported during collection of the data.

Conclusions: The surgical safety checklist is a simple method, and there is evidence for its effectiveness in reducing complications in clinical use. WHO recommends use of the checklist in all surgical operations and encourages clinicians to modify the list for different specialties and hospitals.

Key Words: surgical, safety, checklist, communication.

1 Correspondence author: Assistant professor, Department of Surgery, Al Kindy College of Medicine

2 Professor, Department of Surgery, Al Kindy College of Medicine

3 Assistant professor, Department of Surgery, Al Kindy College of Medicine

$\begin{array}{lr}\text { Received } & \text { at } 4 / 10 / 2017 \\ \text { Accepted } & \text { at14/6/2018 }\end{array}$

\section{INTRODUCTION}

$\mathrm{W}$ orldwide, a wide range of safety problems challenges the delivery of health care. The traditional medical oath' 'first do no harm' 'is rarely violated intentionally by physicians, nurses, or other practitioners, but the fact remains that patients are harmed every day in every country across the globe in the course of receiving health care ${ }^{(1)}$. All patients have safe care at all times ${ }^{(2)}$.

A surgical condition has commonly defined as any condition that requires suture, incision, excision, manipulation, or other invasive procedure that usually, but not always, requires local, regional, or general anesthesia $(3,4)$. Estimates show that approximately 234 million major operations are performed every year ${ }^{(5)}$. Surgery has high rates of morbidity and mortality, at least 7 million people a year experience disabling surgical complications and more than one million die ${ }^{(6,7)}$.

With the growing recognition of safety problems in health care, it is now time to create and disseminate solutions for patient safety problems, therefore, will be intended to promote an environment and support systems that minimize the risk of harm despite the complexity and lack of standardization in modern health care confronted with worldwide evidence of substantial public health harm due to inadequate patient safety; The World Health Assembly [WHA] in 2002 adopted a resolution urging countries to strengthen the safety of health care and monitoring systems ${ }^{(8)}$. The resolution also requested that WHO take a lead in setting global norms standards and supporting country efforts in preparing patient safety policies and practices ${ }^{(9)}$.

The goal of the Safe Surgery Saves Lives Challenge is to improve the safety of surgical care around the world by ensuring adherence to proven standards of care in all countries ${ }^{(10)}$. Surgical safety crippled by its lack of recognition as a public health problem. WHO patient Health safety issues, inadequate 
anesthetic safety practices, avoidable surgical infection and poor communication among team members established the Safe Surgery Saves Lives programe ${ }^{(11)}$.

These have proved to be common deadly and preventable problems in all countries and settings. Complications of anesthesia also remain a substantial cause of death during surgery globally despite safety and monitoring standards that have reduced the numbers of unnecessary deaths and disabilities in industrialized countries ${ }^{(12)}$.

The WHO surgical safety checklist identifies a set of surgical safety standards that can be applied in all countries and health settings. The strategy is to define a simple set of minimum standards for surgical care that are practical and can be universally applied across countries and settings. Between October 2007 and September 2008, eight hospitals in eight cities [Toronto, Canada; New Delhi, India; Amman, Jordan; Auckland, New Zealand; Manila, Philippines; Ifakara, Tanzania; London, England; and Seattle] representing a variety of economic circumstances and diverse populations of patients participated in the World Health Organizations Safe Surgery Saves Lives program ${ }^{(13)}$. Its use has been demonstrably associated with significant reductions in complication and death rates in diverse hospitals and settings, and with improvements in compliance to basic standards of care. Most research has been done on hospital [secondary] care in developed countries and these studies show an adverse event rate of about $10 \%$, that is to say, one in every ten patients admitted to hospital suffers an adverse event ${ }^{(14)}$.

The WHO surgical safety Checklist divides the operation into three phases, each corresponding to a specific time period in the normal flow of a procedure: the period before induction of anesthesia (Sign In), the period after induction and before surgical incision (Time Out), and the period during or immediately after wound closure but before removing the patient from the operating room (Sign Out) ${ }^{(15)}$. In each phase, the Checklist coordinator must be permitted to confirm that the team has completed its tasks before it proceeds further. This designated Checklist coordinator will often be a circulating nurse, but it can be any clinician or healthcare professional participating in the operation ${ }^{(16)}$.
As operating teams become familiar with the steps of the Checklist, they can integrate the checks into their familiar work patterns and verbalize their completion of each step without the explicit intervention of the Checklist coordinator ${ }^{(16)}$. Each team should seek to incorporate use of the Checklist into its work with maximum efficiency and minimum disruption, while aiming to accomplish the steps effectively ${ }^{(17,18)}$.

The WHO identifies ten essential objectives for safe surgery:

1) The team will operate on the correct patient at the correct site.

2) The team will use methods known to prevent harm from administration of anesthetic, while protecting the patient from pain.

3) The team will recognize and effectively prepare for life threatening loss of airway or respiratory function.

4) The team will recognize and effectively prepare for risk of high blood loss.

5) The team will avoid inducing an allergic or adverse drug reaction for which the patient is known to be at significant risk.

6) The team will consistently use methods known to minimize the risk for surgical site infection.

7) The team will prevent inadvertent retention of instruments and sponges in surgical wounds.

8) The team will secure and accurately identify all surgical specimens.

9) The team will effectively communicate and exchange critical information for the safe conduct of the operation.

10) Hospital and public health system will establish routine surveillance of surgical capacity, volume and result ${ }^{(19) .}$

This study aims to reduce the disability and deaths associated with surgery by improving team communication and consistency of care.

\section{METHODS}

We prospectively collected data on clinical processes and outcome from consecutively enrolled patients. We applied the 19 items of the WHO checklist to all patients. These were done by the resident doctors and with collaboration of anesthetist and nursing staff at the surgical theater at Al-kindy Teaching Hospital during the period from the $1^{\text {st }}$ September 2016 till the $1^{\text {st }}$ of March 2016. 
The surgical interventions include elective cases after full preparation and emergency cases. Data collected including the age, gender and other clinical evaluation had already been taken during preparation for surgery.

The 19 parameters of the checklist used in this study is divided into three phases. Phase I before the patient get anesthesia consists of identity, site, procedure, consent, marking the site of operation, pulse oximetry, check for anesthetic machine and its drug, allergy to drugs, risk of difficult airway and risk of blood loss. Phase II before skin incision consists of introduction of the member in the theater to the patient, verbally confirmation of name, site, and type of the procedure. In addition, it contains the anticipated critical event during surgery, antibiotic prophylaxis, and imaging displayed.

Phase III before patient leaving the operative room, the list consists of name of the procedure, instruments, gauze count, how the specimen labeled, any equipment problem, any concern regarding the recovery and the management of this patient.

The primary ends were the rate of complications, including surgical site infection, respiratory problems and death taken during hospitalization and within the first 30 days after the operation. Then we correlated the occurrence of the postoperative complications with each parameter above. The results are shown in the form of tables statistically described.

The statistical package for the social science (SPSS) version 22 was used to enter and analyze data. The confidence at $95 \%$ and the $\mathrm{P}$ value is significant when equal or less than 0.05 .

Mean standard deviation (SD) and frequency distribution was calculated.

Statistics done using Chi-square or $\mathrm{Z}$ score analysis for categorical variables

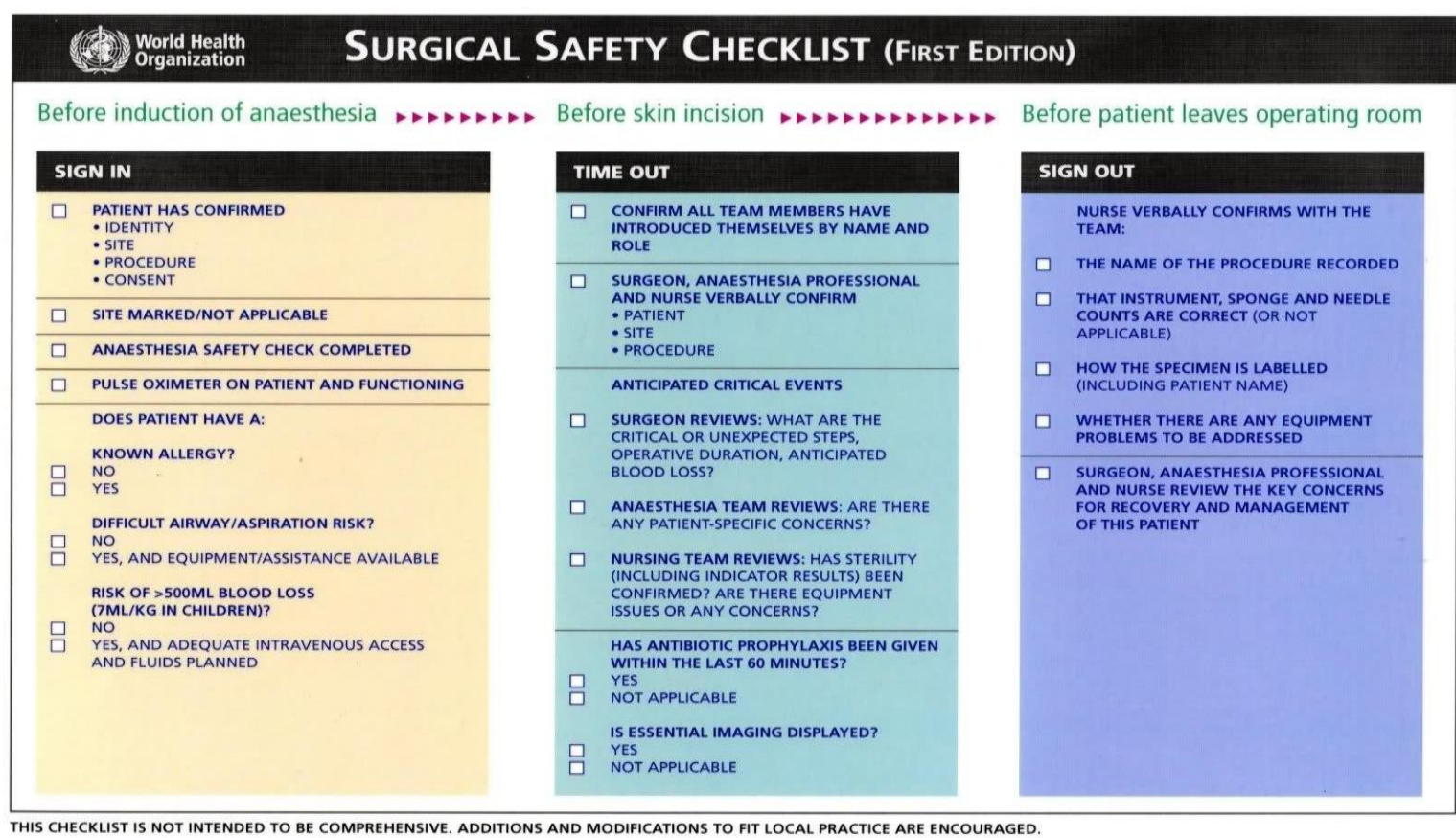

\section{RESULT}

The study included 300 enrolled patients submitted to elective and emergency operations and the 19 items of the checklist were applied to all patients in this study.

In phase I before induction of anesthesia [table 1] the identity of the patient was checked in 296 [98.6\%] patients, the site in 290 [96.7\%] patients, type of procedure in 278 [92.6\%] patients, and the consent in
280[93.3\%] patients. The site for operation was marked in 196 [65.3\%] patients. The use of pulse oximetry used in 282 [94\%] patients. Anesthesia safety checked in 288[96\%] patients. Allergy to drugs checked in 292 [97.3\%] patients, from those 18[5.7\%] had drug allergy. Difficulty in airway checked in 294 [98\%] patients, 4 [2.6\%] of them had airway difficulty. Risk of blood loss checked in 284 [94.6\%] patients, of those 26 [8.66\%] had risk of blood loss and preparation done. 
In the phase II before skin incision [table 2], the nurse confirms the name of the patients, site and the type of procedure in 298 [99.3\%] patients Anticipated critical events (where the surgeon asked for how long the duration of operation or if there is risk of blood loss) in 140 [46.6\%] patients the anesthetist asked for any patient specific concern in 146 [48.7\%] and the nursing team review in 24 [8\%]. Antibiotic prophylaxis given in 190 [63.3\%] patients, and extended regime in 110 [36.67\%] and the imaging displayed in 134 [44.6\%] patients.

In the phase III, before the patient leave the operative room [table 3], the nurse verbally confirms the name of the procedure in 294 [98 $\%$ ] patients, instruments and gauze count in 232 [77.3\%] patients, specimen labeled in 190 [63.3\%] patients and equipment problems in 34 [11.3\%] patients The anesthetist concerned the recovery of the patients in 218 [72.6\%] cases.

During the follow up period [Table 4, 5], some patient had developed surgical site infection in 42 [14\%]; Of those patients $12[4 \%]$ received antibiotic prophylaxis within one hour before operation and another two doses post operatively, and $30[10 \%]$ continue on extended regime. The number of patients with no wound infection and received extended regime was 80 [26.6\%] and those who received antibiotic prophylaxis with no infection 178[59.33\%] The p-value $=0.003$ which is highly significant using chi square test for that group. Airway difficulties occur in 8 [2.6\%] patients and respiratory complication is $14[4.6 \%$ ] and missed gauze in $2[1.3 \%]$ cases.

Table 6 shows the characteristic of the procedure with respect to the outcomes and the regime of the antibiotic, we found in 86 [28.6\%] of emergency patients, the SSI in 28 [9.3\%], antibiotic prophylaxis in 38 [12.6\%], the extended regime in 48 [16\%], airway difficulties in $2[0.6 \%]$ and respiratory complications in 4 [1.3\%] cases. In 214 [71.3\%] of the elective cases we found SSI in 14 [4.6\%] cases, antibiotic prophylaxis 152 [50.6\%], Extended regime of antibiotic in 62 [20.6\%], airway difficulties in $6[2 \%]$ and respiratory complications in 10 [3.33\%]. No mortality occurs in both groups.

Table (1): Number of patients checked before induction of anesthesia $(N=300)$

\begin{tabular}{|c|c|c|}
\hline Parameter & No. of patients Checked & percent \\
\hline Identity & 296 & 98.6 \\
\hline Site & 290 & 96.7 \\
\hline Consent & 280 & 93.3 \\
\hline Procedure & 278 & 92.6 \\
\hline Site marked & 196 & 65.3 \\
\hline Pulse oximetry & 282 & 94 \\
\hline Anaesthetic safety Check & 288 & 96 \\
\hline Drug allergy & 292 & 97.3 \\
\hline Airway difficulty & 294 & 98 \\
\hline Risk of blood loss & 284 & 94.6 \\
\hline
\end{tabular}

Table (2): Number of patients checked before skin incision $(\mathrm{N}=300)$

\begin{tabular}{|c|c|c|c|}
\hline \multicolumn{2}{|c|}{ Parameters } & No. of patients & Percent \\
\hline \multicolumn{2}{|c|}{ Nurse confirmation } & 298 & 99.3 \\
\hline \multirow{3}{*}{ Anticipated critical Events } & Surgeon & 140 & 46.6 \\
\cline { 2 - 4 } & Anesthetist & 146 & 48.7 \\
\cline { 2 - 4 } & Nurse & 24 & 8 \\
\hline \multicolumn{2}{|c|}{ Antibiotic prophylaxis } & 190 & 63.3 \\
\hline \multicolumn{2}{|c|}{ Imaging displayed } & 134 & 44.6 \\
\hline
\end{tabular}


Table 3: Number of patients checked before patient leaving the operative room $(\mathrm{N}=300)$

\begin{tabular}{|c|c|c|}
\hline Parameters & No. of patients & Percent \\
\hline Name of procedure & 294 & 98 \\
\hline Instruments count & 232 & 77.3 \\
\hline Specimen labeled & 190 & 63.3 \\
\hline Equipment problem & 34 & 11.3 \\
\hline Reviewing the recovery of the Patient & 218 & 72.6 \\
\hline
\end{tabular}

Table 4: Relation of SSI to the Antibiotic prophylactic or to Extended regime ( $\mathrm{N}=300)$

\begin{tabular}{|l|c|c|}
\hline \multicolumn{1}{|c|}{ Parameter } & Antibiotic Prophylaxis & Extended Regime \\
\hline Surgical site infection & $12(4 \%)$ & $30(10 \%)$ \\
\hline No infection & $178(59.3 \%)$ & $80(26.6 \%)$ \\
\hline Total number & $190(63.3 \%)$ & $110(36.67 \%)$ \\
\hline
\end{tabular}

Table 5: Complications during and after completion of surgery $(\mathrm{N}=300)$

\begin{tabular}{|l|c|c|}
\hline \multicolumn{1}{|c|}{ Complications } & No. of patients & Percent \\
\hline Airway difficulty & 8 & 2.6 \\
\hline Blood loss & 26 & 8.66 \\
\hline Respiratory complications & 14 & 4.6 \\
\hline Surgical site infection & 42 & 14 \\
\hline Retained gauze & 2 & 0.66 \\
\hline Death & 0 & 0 \\
\hline
\end{tabular}

Table 6: Elective and emergency cases with respect to the outcome of the procedure and regime of antibiotic. $(\mathrm{N}=300)$

\begin{tabular}{|c|c|c|c|c|c|}
\hline \multirow{2}{*}{$\begin{array}{c}\text { Type of } \\
\text { Surgery (\%) }\end{array}$} & SSI & \multicolumn{2}{|c|}{ Antibiotic } & \multirow{2}{*}{$\begin{array}{c}\text { Airway } \\
\text { Difficulty }\end{array}$} & $\begin{array}{c}\text { Respiratory } \\
\text { complications }\end{array}$ \\
\cline { 3 - 4 } & & Prophylaxis & Extended regime & & 4 \\
\hline Emergency cases & 28 & 38 & 48 & 2 & 4 \\
N=86 [28.6\%] & {$[9.3 \%]$} & {$[12.6 \%]$} & {$[16 \%]$} & {$[0.6 \%]$} & {$[1.3 \%]$} \\
\hline Elective cases & 14 & 152 & 62 & 6 & 10 \\
$\mathrm{~N}=214[71.3 \%]$ & {$[4.6 \%]$} & {$[50.6 \%]$} & {$[20.6 \%]$} & {$[2 \%]$} & {$[3.33 \%]$} \\
\hline
\end{tabular}

\section{DISCUSSION}

Surgical complications are considerable causes of death and disability around the world. They are preventable, though their prevention typically requires change in systems and individual behavior.

Introduction of the WHO surgical safety Checklist into operating rooms in our hospital was comparable in surgical outcome with Alex B. Haynes et al ${ }^{(20)}$. Regarding the surgical site infection in our study was $4 \%$, which is nearly the result in Alex B. Haynes et al, was 3.4\%. This result was lower after the introduction of the prophylactic antibiotic comparing with result of study for SSI done at Al-Yarmouk teaching hospital, which was $16.4 \%$ using extended antibiotic regime $^{(21)}$, and this low result show the effectiveness of giving antibiotic within one hour before skin incision with p-value 0.0003 which is highly significant using chi square test .

The checklist in our study for patient Identity, consent and procedure was $(98.6 \%$, $93.3 \% \& 92.6 \%$ ) respectively compared with $(90 \%, 82 \%$ \& $90 \%)$ in Stephanie et al ${ }^{(22)}$. And 
for pulse oximetry, anesthesia safety check, airway difficulty and drug allergy was $(94 \%$, 96\%, 98\% \& 97\%) which compared with $(100 \%, 82.5 \%, 92.5 \%$ \& $85 \%)$ respectively in Dominique Mc Ginlay et al ${ }^{(23)}$.

In this study although not all the patients had marked the site of the surgery but there were no wrong site surgery happened during collection of the patients. And to localization of the site of operation we did case sheetwriting and verbally confirming the site of the procedure, while in the study done in UK they reviewed from Research and learning System (RLS) database (September 2007 August 2008) revealed $26(3.6 \%)$ cases of wrong patients ${ }^{(24)}$.

In other recent study revealed 5,940 cases of wrong site surgery $(2,217$ of them wrong side surgical procedures and 3,723 wrong treatmentlprocedure errors) in 13 years ${ }^{(25)}$. The development of pneumonia as a respiratory complication in this study occur in 14 [4.6\%] patients, 8 (2.6\%) of these cases occur in patient developed respiratory embarrassment during the operation while in Haynes et al the risk was [1.3\%] ${ }^{20}$, and in study done by Syed Abdullah Iqbal et al shows respiratory tract infection in [7.0\%] patients ${ }^{(26)}$.

In this study the gauze and instrument counting done only in 116 [77.3\%] as the nurse count them just when there were open cavities, but 2 [0.6\%] patients had missed gauze; one of them intra.abdominal and the other in subcutaneous tissue and this happened due to missed counting of the small gauze that cannot be seen at the end of operation. In the study done by Hyslop JW. et al ${ }^{(27)}$ there was one case of missed gauze out of every $1000-1500(0.1 \%)$ intra-abdominal operations.

There was no mortality in this study comparing with Haynes et al [0.8\%], and in study done by Syed Abdullah Iqbal et al the mortality rate was $\left[0.9 \%{ }^{(26)}\right.$. Owing to the small sample of our study and most of the cases were elective cases with full preoperative evaluation and preparation for surgery and most of the emergency cases were of short duration with no risk of bleeding or other factors that affect the patient general health, in addition to the application of the checklist and well preparation done preoperatively.
In the outpatient procedures patients there is limitation in collection of outcome data as it ceased on their discharge from the hospital on the day of the procedure, so they did not affect as much the rates of complications because of its small number. In other studies the limitations of the study might have led to an underestimation of the number of deviations, because of decreased diligence to ensure that everything went according to protocol ${ }^{(28)}$.

There is difficulty to select personnel to act as checklist Coordinator. We faced also variable response to checklist among the medical staff as they think they are watched. This checklist program has the potential to prevent large numbers of deaths and disabling complications, although further study needed to determine the precise mechanism and durability of the effect in specific setting.

\section{CONCLUSION}

This study showed that application of checklist can decrease the number and percentage of complication \&death rate postoperatively.

\section{Recommendations:}

1- Any physician should discuss with the patient the operative plans, risks and complications.

2- Post-operative team debriefing to discuss problems during the case and concerns for recovery, management and follow-up of the patient.

\section{REFRENCES}

1) WHO Collaborating Centre for patient Safety Solutions patient safety solutions preamble; The Joint Commission International. http; \www.WHO.int। programmes. May 2007;1-3

2) Classen," The Timing of Prophylactic Administration of Antibiotics and the Risk of Surgical-Wound Infection". New England Journal of Medicine, 1992; 326(5):281-6.

3) Vats A, Vincent CA, Nagpal K, Davies RW, Darzi A, Moorthy K. Practical challenges of introducing WHO surgical checklist; UK Pilot experience. BMJ. 2010 13; 340; b5433.

4) Voss, C., Tsikriktsis, N. and Frohlich, M. Case research in operations management. Inter. of Operations and production Management 2002; 22, 2, 195-219.

5) Weiser TG, Regenbogen SE, Thompson, KD, et al. An estimation of the global volume of surgery; a modelling strategy based on 
available data. Lancet 2008; Published online June 25. DOI; 10.1016।S0140-6736[08]60878-. $\mathrm{Ptt}$;।www.WHO.int

6) Washington, DC; Population reference bureau, 2006. http; |lwww.prb.orglworld population data sheet. 2006; 7-12.

7) Gawande AA, Thomas EJ, Zinner MJ et al. The incidence and nature of surgical adverse events in Colorado and Utah in 1992. Surgery; 1999; $126 ; 6675$.

8) World Health Organization. Surgical safety checklist [first Edition].http; \www.who. int patient safety\ safe surgery\ tools resources\ SSSL Checklist finalJun08.pdf

9) World Health Organization. "WHO Guidelines on Hand Hygiene in Health Care. Geneva, World Health Organization", Cambridge University Press, 2009; pp.611-22.

10) Implementation manual WHO surgical safety checklist; Safe surgery saves lives.ptt;\ www.ncbi.nlm.nih.org. 2009; 6p.

11) Safe Surgery Saves Lives -Background paper [DRAFT], First international Consultation Meeting WHO Headquarters, Geneva, Switzerland 11th-12th January 2007

12) Leape LL. Error in Medicine. JAMA 1994; 272[23]; 1851-7

13) Starfield B, Balancing Health Needs, Services and Technology $8^{\text {th }}$ ed., New York; Oxford University press. 1998;pp. 15-8.

14) Debas H, et al. "Surgery" in Disease Control priorities in Developing Countries, 2 ed. Disease Control priorities project; The International Bank for Reconstruction and Development / The World Bank, 2006

15) C. Vijayasekar. R.J.C Steele. The World Health Organization's surgical safety checklist.2009; 7 ( 5); 4 .

16) World Health Organization. Prevention of hospital acquired infections; a practical guide.2nd. Geneva, 2002.

17) Chin J,editor. Control of communicable diseases manual. 17th ed. Washington DC; American public Health Association, 2000. $624 p$.
18) Ronald L Nichols. Preventing surgical site infections; the surgeon's perspective. Emerg .Infect Dis.;2001; 2 [7]; 220-4.

19) D.W. Bratzler and P.M.Houch, the American Journal of Surgery, ( 2005) 395404.

20) Haynes AB, Weiser TG, Berry WR, Lipsitz SR, Breizat AH,Dellinger EP et al A surgical Safety checklist to reduce morbidity and mortality in a global population. N Engl J Med.2009Jan 29; 360[5]; 491-9.

21) Latif M. Shinawa. Factors influence wound infections in abdominal surgery at Al-Yarmouk Teaching Hospital Iraqi board for medical specialties [surgery]. 2008;10-2.

22) Stephanie Russ,PhD. Shantanu Rout,MRCS. Measuring variation in use of the WHO surgical safety checklist in operative room. Journal of the American College of Surgeons. 2014;220(1);3-6.

23) Dominique McGinlay, Derick Moore, Aurel Micronescu. A prospective observational assessment of surgical safety checklist use in Brasove Children Hospital. Romanian Journal of Anesthesia and Intensive Care 2015;22(2);11121.

24) Sukhmeet S Panesar. The WHO checklist; a global tool to prevent errors in surgery. PSS Journal;9,2009.http;//www.pssjournal.com/cont ent $/ 3 / 1 / 9$.

25) Seiden SC, Barach P; wrong-side/wrong procedure, and wrong patients adverse events; Are they preventable Arch Surg 2006, 141[9]; 931-9.

26) Masood Jawaid, zubia Masood, Syed Abdullah Iqbal. Post- operative Complications in a General Surgical Ward of a Teaching Hospital. Pakistan Journal Of Medical Sciences. 2006;22(2); 171-7.

27) Hyslop JW, Maull KI Natural history of the retained surgical sponge. Southern Medical Journal, 1982, 75; 657-60.

28) De Vries EN', Hollmann MW, Smorenburg SM, Development and validation of the Surgical Patient Safety System Ptt;/lwww.Pubmed.com.2009;p4. 